\title{
A ERVA-MATE E AS TRANSFORMAÇÕES SOCIOECONÔMICAS E POLÍTICAS NO PARANÁ ${ }^{1}$
}

Roberta Carnelos RESENDE ${ }^{2}$

\author{
Recebido em: 31/08/2016 - Aprovado em: 05/10/2017 - Disponibilizado em: 30/12/2017
}

\begin{abstract}
RESUMO
Este artigo tem como objetivo fazer uma análise do papel da produção da erva-mate enquanto motor das mudanças econômicas, sociais e culturais, ocorridas nos séculos XIX e nos primeiros decênios do século XX, mais especificamente do período que se inicia com a emancipação política da Província do Paraná. As mudanças no processo produtivo, as fragilidades do comércio, as diversas regulamentações dessa atividade, a implantação de infraestrutura de transportes, políticas educacionais, populacionais e culturais, promovidas, sobretudo, com a ascensão de uma fração burguesa industrial, deixaram suas marcas nas instituições tradicionais do Estado até os dias atuais, podendo ser analisado como um processo civilizatório.
\end{abstract}

Palavras-chave: história econômica, Paraná, erva-mate, processo civilizatório.

\section{YERBA MATE AND THE SOCIOECONOMIC AND POLITICAL TRANSFORMATIONS IN PARANÁ}

\begin{abstract}
The goal of this article is to analyze the role of the yerba mate production as an engine of the economic, social, and cultural changes that occurred in the 19th century and in the first decades of the 20th century, focusing specifically on the period that begins with the political emancipation of the Province of Paraná. The changes in the production process, the weaknesses of the market, the various regulations of this activity, the implementation of the transportation infrastructure, educational, population and cultural policies, promoted, especially, with the rise of a bourgeois industrial fraction, leaving their mark in traditional institutions of the State until the present, therefore they can be analyzed as a civilizing process.
\end{abstract}

Key-words: economic history, Paraná, yerba mate, civilizing process.

\footnotetext{
${ }^{1}$ Este trabalho é parte da monografia de graduação intitulada "A Erva-Mate e as Transformações Socioeconômicas no Paraná", apresentada pela autora em 2006, na Universidade Federal do Paraná.

2 Doutoranda em Ciência Política (UFRGS), Mestre em Sociologia (UFPR) e Bacharel em Ciências Econômicas (UFPR). E-mail: roberta_carnelos@yahoo.com.br 


\section{INTRODUÇÃO}

A erva-mate, embora abundante nas matas nativas, teve importância secundária na economia paranaense anterior ao século XIX, sendo a planta utilizada predominantemente para consumo próprio e pequenas trocas. Alguns eventos históricos relacionam-se diretamente com a transformação da erva em mercadoria de exportação, como também visualizam a posição do mate paranaense no cenário internacional, e em menor grau no Brasil.

O caráter eminentemente exportador do mate paranaense distinguiu-se de outros produtos de exportação do Brasil, pois, seu mercado de maior expressividade foram os países platinos, e não as economias industrializadas. A atividade de colheita da erva-mate se desenvolveu em praticamente todo o "Paraná Tradicional", com exceção do litoral, que muito se beneficiou, pois, sendo um produto destinado essencialmente a exportação se constituiu no ponto de saída para o mercado externo. No litoral, Paranaguá, "devido ao seu movimentado porto, foi o principal centro catalisador $\mathrm{e}$ irradiador das novidades chegadas de outros locais" (LEANDRO, 1999, p.1) bem como o maior exportador da congonha. O porto de Antonina, embora de menor expressividade quanto à quantidade de exportação, foi de extrema importância para a economia ervateira no Paraná. Contudo, a falta de vias de comunicação fez-se um grande obstáculo

para esta atividade até as últimas décadas do século XIX, quando foi concluída a estrada da Graciosa, e inaugurada a ferrovia ligando Curitiba à Paranaguá.

Posteriormente, no litoral, além dos benefícios proporcionados pela atividade portuária, sua importância foi estendida para o processo de beneficiamento da erva-mate, com número expressivo de moinhos e casas de soque na região. As modificações ocorridas no processo de beneficiamento da erva-mate foram intensificadas pela introdução de novas técnicas, trazidas principalmente por agentes hispanoamericanos, conhecedores do processo paraguaio, que proporcionou o produto de melhor qualidade na época, e posteriormente provindos da Europa, onde presenciou maior desenvolvimento da divisão do trabalho amparado em novas tecnologias, dando origem, entretanto, as indústrias complementares ao mate.

A atividade ervateira constituiu em fator decisivo para a emancipação política do Paraná, em 1853, sendo a principal atividade econômica no estado até meados da segunda década do século XX, e representando, segundo LINHARES (1969), o imposto sobre exportação do mate, aproximadamente metade do total de sua receita estadual. A intensificação do comércio ervateiro e da infraestrutura paranaense viabilizou o aparecimento de novos negócios, bem como da reordenação política e jurídica do estado, 
fruto de intensas disputas entre os bacharéis ${ }^{3}$ dos Campos Gerais e a burguesia ervateira. Porém, questões relacionadas à qualidade da erva, ao processo de produção, e a instabilidade do comércio exterior proporcionaram as grandes flutuações no mercado ervateiro.

Com a modernização e urbanização propiciada pela economia ervateira, Curitiba tornou-se um centro de irradiação cultural, demandada pelas novas personalidades. Nesse processo surgiram instituições tradicionais nos campos da sociabilidade e cultura, que perduram até os dias atuais, caso da Universidade Federal do Paraná, da Associação Comercial do Paraná e do Clube Curitibano. Observou-se uma modificação no desenho urbano da cidade, como também no pensamento e no comportamento do homem urbano já no último quartel do século XIX.

A transformação dos costumes e tradições foi uma exigência deste "processo civilizatório". As relações sociais entre os indivíduos diversificaram-se, desde as relações de produção, com substituição do trabalho escravo pelo assalariado, mesmo antes da abolição da escravatura em 1888, processo peculiar ao Estado do Paraná.

O presente artigo está organizado em duas seções principais: a primeira abordará a

\footnotetext{
${ }^{3}$ Segundo MAGALHÃES (1972, p. 26) “os bacharéis (eram identificados aqueles que atingiam um grau de instrução mais elevado), na maior parte das vezes filhos ou sobrinhos dos proprietários rurais e comerciantes...".
}

história da erva-mate até meados do século XIX, e, a segunda seção analisará as transformações sociais, iniciadas no final do século XIX, advindas da econômica ervateira no estado do Paraná. Por fim, nas considerações finais serão apresentados os principais achados deste trabalho.

\section{ERVA-MATE: DA ORIGEM ATÉ 1853}

A história econômica do mate remonta ao período da colonização europeia, mas especificamente quando o General Irala desbravava o Paraguai chegando em Guairá, por volta de 1554. Ao chegar na região, percebeu que os índios de Guairá eram mais fortes que os guaranis e o mais curioso era que eles faziam uso generalizado da bebida feita de folhas fragmentadas, tomada em cuia por meio de um canudo de taquara (LINHARES, 1969). Posteriormente, o canudo de taquara foi substituído pela bomba metálica. Boa parte dos hábitos sociais da erva-mate foram descritos pelos viajantes que por aqui passaram:

\footnotetext{
O chimarrão, que é ao mesmo tempo um rito social e um vício privado, tal como se prática na fazenda... Os primeiros goles provocam uma sensação deliciosa feita do contato meio viscoso da prata escaldada, da água efervescente, rica de uma espuma substancial; amarga e cheirosa ao mesmo tempo, como uma floresta inteira concentrada em algumas gotas. (LEVISTRAUSS, p.55, 1998)

O mate utilizado no chimarrão, a forma mais tradicional de ingestão da erva, "tem desempenhado papel ativo, favorecendo a cordialidade como elemento já característico
} 
de nossa civilização; aqueles traços de generosidade, acessibilidade, intimidade, lhaneza de trato, hospitalidade, foram sem dúvida fecundados e estimulados por ele" (LINHARES, 2000).

Retornando ao contexto histórico do mate, LINHARES (1969) salienta que os soldados do General Irala foram os primeiros não índios a fazer uso da erva-mate, que foi, aos poucos, difundindo-se nos lares espanhóis, dando início a um conjunto de relações econômicas de maior importância.

Os jesuítas, que inicialmente a combateram, se tornariam os seus melhores difusores, contribuindo para o melhoramento da erva, como também se dedicando na plantação do mate. Neste período, a erva-mate ficou conhecida como "chá dos Jesuítas", e seu processo de produção ficou restrita a estes homens até meados do século XVIII, quando ocorreu a saída forçada da Companhia de Jesus das terras da América (LINHARES, 1969).

Embora no século XVIII a erva-mate já fosse conhecida no Paraná, era mantida uma produção apenas para consumo local. Foi com a vinda do Ouvidor Raphael Pires Pardinho $^{4}$ em 1721, que verificando a existência da erva-mate, planta nativa da região, vislumbrou a possibilidade de melhorar a vida daquela população pobre

4 Advogado português que fora nomeado Ouvidor Geral da Capitania de São Paulo em 1717, e que assumiu a liderança no processo de organização das terras, da economia, e ordens jurídicas, de Curitiba e Paranaguá (Linhares, 1969). solicitando ao rei que liberasse aos habitantes o comércio da congonha, madeira, farinha de mandioca, betas, com a Nova Colônia do Sacramento, o pedido foi atendido através da Carta Régia de 29 de Abril de 1722. (LINHARES, 1969)

Esta carta foi uma atitude pensada no sentido de "fortalecer a economia de mercado ampliado, uma vez que as comunidades rurais semi-isoladas, que eram os municípios paranaenses, tendiam a regredir à pura autosubsistência e a praticar o escambo para a obtenção de alguns produtos europeus." (BALHANA et alli., 1969)

Em sua passagem pelo Paraná, Ouvidor Pardinho percebeu ainda, que a miséria do litoral do Paraná provinha não apenas da preguiça, como da inexistência de comércio que não fosse das pescarias, farinhas de pau e alguma cordoaria de imbé, utilizadas para permutas principalmente com vestuário das embarcações vindas de Santos e do Rio de Janeiro. (VIEIRA DOS SANTOS apud PEREIRA, 1996, p. 29).

As contribuições do Ouvidor foram ainda maiores, pois, tomou várias providências para viabilizar a construção do porto de Paranaguá, entre elas a concessão de terrenos e as análises necessárias no que se refere às áreas onde deveria ser construído o cais.

O descontentamento da maioria da população local com a agricultura de subsistência e o precário comércio de 281

Revista da Universidade Vale do Rio Verde, Três Corações, v. 15, n. 2, p.278-295, ago./dez. 2017 
excedentes evidenciou-se, principalmente, dos restritos mercados urbanos onde a produção agrícola seria negociada, e também por acreditarem que esta alternativa não era a mais interessante para a participação no mercado. (PEREIRA, 1996)

$\mathrm{Na}$ visão de PEREIRA (1996), as correições do Ouvidor foram reflexo das preocupações da deficitária coroa portuguesa, que viam no comércio o grande propulsor da integração territorial da colônia e ainda mais, já que da precária economia de subsistência e escambo pouco se arrecadava em tributos.

Com a convocação de jovens para a Companhia de Auxílio do Regimento, em 1768, a população que se dedicava à mineração reduziu-se para menos de $10 \%$ do total, e essa atividade tornou-se antieconômica (IANNI, 1988). A população que já vivia em estado de pobreza, produzindo apenas o necessário para a subsistência ficou com a situação ainda mais agravada como se pode notar na apresentação de LINHARES (1969, p. 77):

Há uma referência no termo de vereança de 14 de maio de 1777, da Câmara de Curitiba, digna da maior atenção, como de resto, ocorre com todo o termo, que tratava do abastecimento ao exército de 6 mil homens mandados de São Paulo para Lajes em ajuda às forças que em Santa Catarina haviam sido atacadas pela esquadra espanhola, já então desembarcada na ilha do Desterro. (...) A requisição oficial de gêneros e gente, além de animais e reses, imposta ao pobre Conselho Municipal de Curitiba, representava esforço quase sobrehumano a ser levado a cabo pelos aflitos munícipes curitibanos, a quem ainda se reclamava maior diligência e eficiência.

A expansão da economia do mate coincidiu com um período em que Paranaguá e Curitiba começaram a sofrer o impacto da decadência da mineração: "a canalização de força de trabalho e capital para a extração, preparo e comércio da congonha, entretanto, é em boa parte o resultado da liberação desses fatores de produção" (IANNI, 1988). O trabalho e os recursos aplicados à mineração de aluvião tinham a necessidade de encontrar outra atividade produtiva com a extinção do ouro, e inicialmente migraram para a agricultura e pecuária.

Considerando-se a decadência da mineração, o aumento da miséria dos habitantes do planalto, e todas as questões elucidadas anteriormente, a extração da ervamate tornou-se uma boa alternativa para a obtenção de renda (PEREIRA, 1996, p.47).

A população se adaptaria rapidamente à atividade ervateira, e já no final do século XVIII, sua produção vai além da necessária a subsistência, gerando excedentes, e dando início à sua comercialização. (IANNI, 1988)

Na década de 1720, a produção era tão rudimentar e o produto de baixa qualidade que muitos pensavam não se tratar da mesma planta encontrada no Paraguai, assim, mesmo com a liberação do comércio, esse foi incipiente, limitando-se a pequenas permutas com os barcos que aportavam em Paranaguá. Dessa data até a década de 1820 houve o que pode ser considerado o "século perdido" do comércio ervateiro: "Se os paranaguenses 
fossem especuladores comerciais, desde então quantos milhões de riqueza teriam acarretado de Buenos Aires de 1722 a 1822?" (CARNEIRO, p.20, 1963).

A inexistência de uma burguesia urbana independente juntamente com as dificuldades de comunicação com as províncias platinas e a concorrência dos jesuítas, detentores desse mercado até meados do século XVIII sendo sucedidos pelos paraguaios, foram algumas das causas responsáveis pela insignificância do comércio ervateiro neste período. (LINHARES, 1969, p.72)

A precariedade do processo de estruturação da erva foi também um atenuante para a restrição deste comércio. A rusticidade dos pilões de soque manuais movido pela mão de obra escrava negra e de índios pode ser visto como uma ilustração deste processo.

A coleta da erva-mate é o "início do processo de trabalho nos ervais naturais" (OLIVEIRA, 2001a, p.74). Na primeira etapa é feito o corte dos galhos da árvore, deixando certa quantidade de folhas perto dos galhos mais grossos para que ela possa se reproduzir. Depois do corte, os galhos são submetidos, ainda no mesmo dia, ao sapeco, ou tostada rápida dos galho, que posteriormente são quebradas e unidas em molhos de erva que são levados à secagem. Nesta etapa a erva é submetida ao calor indireto por volta de dez horas, de maneira constante. Sobre esta fase do processo, e a finalização do mesmo, OLIVEIRA (2001) ressalta que:

\begin{abstract}
Para a realização da secagem é preciso uma rústica suspensão de paus e cobertura denominada de carijó. Um aperfeiçoamento dessa estrutura resulta no barbaquá que evita o contato mais direto com a fumaça, através da colocação de canais e ductos para o calor. Terminada a secagem segue-se ao cancheamento ou a trituração. Como no sapeco, existe um prazo para que a qualidade do produto não se deteriore. Depois da secagem deve-se canchear ou malhar o produto em até três dias. Para isso utilizam-se porretes que reduzem o produto a quase um pó de folhas e gravetos. Este depois é peneirado para que resíduos a partir de certo tamanho sejam afastados. (idem, p.74)
\end{abstract}

Deste processo resulta a erva cancheada, porém, de baixa qualidade, mas já apta ao consumo. Posteriormente, com ascensão dos engenhos e casas de soque, a erva cancheada era beneficiada, garantindo o refinamento e uma maior qualidade.

Foi somente nas décadas iniciais do século XIX, com as dificuldades políticas do Paraguai $^{5}$, que os barcos começaram a vir em busca do deste produto, agora escasso naquela região. O especulador Francisco Alzagaray, argentino que viveu no Paraguai e conhecia as técnicas de produção daquele país, desembarcou em Paranaguá em 1820 e verificou que aquela planta era confirmadamente da mesma espécie daquela utilizada pelos paraguaios, justificando as

\footnotetext{
${ }^{5}$ Em 1813, as exportações paraguaias foram proibidas pelo ditador Dr. Francia e o Brasil tornou-se o único produtor e exportador, transformando a erva-mate numa das maiores riquezas nacionais e tornando Curitiba um grande centro de exportação (Anuário Brasileiro da Erva-Mate,1999, apud Pasinato 2003).
} 
diferenças pela qualidade do clima e da terra. Aproveitando o cenário internacional favorável e a grande possibilidade daquele comércio, Alzagaray implantou a primeira fábrica de beneficiamento do produto em Paranaguá utilizando técnicas paraguaias que propiciaram melhoria na qualidade $\mathrm{e}$ quantidade, e entre as inovações é importante citar o uso de surrões para embalar o mate e facilitar o transporte, viabilizando o comércio ervateiro e podendo concorrer com a erva de outras regiões ( LINHARES, 1969). Neste mesmo ano, Saint Hilaire ${ }^{6}$ desembarca na região e faz algumas observações acerca da erva-mate:

Os historiadores do Paraguai falavam muito de mate, mas tampouco se conhecia a planta, antes que eu lá chegasse que o sábio tradutor da viagem de Azara colocava-a entre as plantas gênero psorálea. Em Paris li, na academia de ciências, um trabalho assim expresso: "Planta interessante cresce em abundância nas matas próximas à Curitiba." É A congonha que fornece a famosa erva do Paraguai. Como à época de minha viagem, as circunstancias políticas tornavam quase impossíveis as comunicações do Paraguai propriamente dito com Buenos Aires e Montevidéu, veio gente em busca do mate à Paranaguá (Anuário 1999;Costa,1995;Linhares, 1969, apud Pasinato 2003, p.34).
Por volta de 1821 chegam ao Paraná novos especuladores como Manuel Miró, catalão que conhecia o processo de fabricação hispano-americano tornando-se proprietário de um engenho em Morretes, e se entrelaçando aos ervateiros litorâneas para ampliação deste ramo, e Antonio Ricardo dos Santos, descendente de proprietários de minas no Paraná, que instalou outro engenho de soque para aproveitamento do mate no litoral. Com esses engenhos, deu-se a aceitação do mate paranaense no exterior (BALHANA et alli, 1969; OLIVEIRA, 2001)

No entanto, a grande oportunidade do Brasil, principalmente do Paraná, na produção e comercialização da erva-mate neste período, deu-se com o abandono dos ervais jesuíticos e com o comércio paraguaio em profundo colapso. Restava à população local adquirirem as técnicas de preparo elaboradas pelos jesuítas, como também aprimorar as novidades trazidas pelos especuladores estrangeiros à região.

A partir dos anos 1820-1830 novos processos produtivos voltados à mecanização e concentração do trabalho começaram a ser introduzidos:

6 Primeiro cientista a classificar e publicar uma nomenclatura para a erva-mate, baseado em exemplares coletados na região de Curitiba, durante suas viagens ao sul do Brasil. Ele enviou amostras da planta para o Museu de História Natural de Paris, onde ocorreu uma mistura com outras amostras, havendo troca de etiquetas de identificação e assim, a erva brasileira foi considerada idêntica à do Paraguai e ganhou o nome de Ilex paraguariensis, reconhecendo que a diferença entre as ervas dava-se apenas do processo de preparo (Anuário 1999;Costa,1995;Linhares, 1969, apud Pasinato 2003).
As influências das técnicas originárias dos países platinos, à expansão comercial com acesso aos mercados platinos e chileno, à expansão dos engenhos no litoral para o planalto, a utilização da energia hidráulica que permite o beneficiamento da erva cancheada nos engenhos, podem ser destacados no aprimoramento do processo produtivo da economia do mate. (HOLLEBEN, 2004, p.71) 
Para LINHARES (1969), o sucesso do mate proporcionou um bem comum a pequenos empresários, a pequenos comerciantes intermediários de matéria-prima e aos que participavam diretamente nos trabalhos de beneficiamento e da produção. Mas, a cobiça pelo lucro imediato, levou muitos a fraudarem e falsificarem o produto, causando prejuízos enormes:

A defraudação de produtos e matérias-primas é um procedimento característico do sistema de putting-out. A adulteração era uma das formas encontradas pelo produtor autônomo para melhorar seus ganhos, o que gerava constantes atritos entre estes e os donos do mercado de exportação. Neste caso, o controle da produção representaria uma disputa entre comerciantes e pequenos produtores pela parte dos lucros obtidos nesse comércio, inclusive daqueles advindos da própria adulteração. (PEREIRA, 1996, p.95)

Já no final do século XVIII, segundo PEREIRA (1996), houve a passagem de um sistema de putting-out para um sistema com características eminentemente fabril, com a introdução de casas de soque, e, posteriormente, com a introdução da tração hidráulica no processo de beneficiamento da erva.

Em 1829, por determinação do regimento das câmaras municipais do império, os vereadores da quinta comarca de São Paulo abriram o debate quanto à regulamentação ${ }^{7}$ da exploração do mate. Este permeou fundamentalmente em torno do

${ }^{7}$ Vieira dos Santos teria se encarregado de enviar à câmara de Paranaguá algumas propostas a serem tomadas visando a impedir a prática da adulteração. (Ver Santos, A. V. dos, Memórias históricas da Vila de Morretes: 1851. Curitiba: Museu Paranaense, 1950). combate à adulteração da erva pela mistura de vegetais inferiores. Tal questão desencadeará papel fundamental na industrialização do mate (PEREIRA, 1996 p.22)

Mesmo com o insucesso de tal regulamentação, devido à discordância de grande parte dos vereadores da comarca, que acreditavam na livre concorrência como a melhor forma de resolver essa imperfeição do mercado, propondo um acordo entre os grandes compradores, os quais deveriam diversificar o preço segundo a qualidade do produto recebido, o que se evidenciará até o terceiro quartil do século XIX.

Por volta de 1850, o impacto da economia do mate se evidenciava diante da agricultura de subsistência, "tornando o mercado urbano um espaço de constantes disputas" (PEREIRA, 1996, p. 28). Foi no campo da política e da economia onde as disputas sobre as regulamentações do mercado se acentuavam.

$\mathrm{O}$ processo de independência nos países platinos, principalmente do Paraguai, que dificultou seu comércio da congonha com a Argentina, e também a abertura dos portos em 1808, foram os acontecimentos políticos que mudaram o rumo da erva-mate nas comarcas de Paranaguá e Curitiba no início do século XIX.

A gradativa substituição do trabalho escravo e consequente inserção da mão-deobra assalariada neste período foram também responsáveis pela dinamização da economia 285

Revista da Universidade Vale do Rio Verde, Três Corações, v. 15, n. 2, p.278-295, ago./dez. 2017 
interna da comarca. Anteriormente aos trâmites nacionais que culminaria com a abolição da escravidão no Brasil em 1888, David Carneiro e Temístocles Linhares afirmam que na quinta comarca de São Paulo a substituição do trabalho escravo pelo trabalho livre deu-se na década de 1830 propulsionado pela introdução da tração hidráulica no preparo da erva-mate. (PEREIRA, 1996, p.45)

Com o aumento das exportações da erva-mate, as dificuldades quanto a questões de infraestrutura foram evidenciadas, destacando-se os percalços encontrados com o transporte da matéria-prima para os portos e a comunicação dos povos de serra acima com o litoral, visto que as estradas eram rudimentares e precárias, despertando, contudo, o interesse do governo da época em tomar providências para sua melhoria, já que a atividade ervateira era muito lucrativa para a comarca. (LINHARES apud PASINATO, 2003).

Do total das exportações do porto de Paranaguá, o mate representou $69,81 \%$ em 1826, um número significativo dado à precariedade das condições de transporte, fato este responsável pela criação da Alfândega de Paranaguá no ano seguinte, e pelo surgimento, em Curitiba, dos primeiros engenhos de beneficiamento da erva-mate. (BALHANA et alli, 1969)

Mas, a expressividade da congonha nas exportações da quinta comarca de São
Paulo foi ainda maior, dado que as exportações do porto de Antonina, por muitos anos reconhecido como o porto do mate por excelência, não fora contabilizado.

Segundo LINHARES (1969), nos anos entre $1830-1850^{8}$, a atividade ervateira do estado expandiu-se com a criação de 70 fábricas de socar a congonha, espalhadas na direção de Curitiba, chegando até a Lapa. E percebendo a lucratividade desta atividade para a Comarca, e com os consequentes incentivos governamentais, no governo de Zacarias de Góis os soques existentes no Paraná já chegavam a noventa.

Por volta de 1850 ocorreu expressivo aumento dos preços do mate no mercado internacional, e consequentemente uma proliferação de engenhos no planalto ${ }^{9}$. Com isso houve um aumento da população local dedicada à economia de mercado, via extração do mate ou como trabalhadores

\footnotetext{
8 " $\mathrm{Na}$ freguesia de Morretes havia 12 fábricas de soque, sendo 11 movidas a água e $1 \mathrm{com}$ animais. Na estrada do Arraial, 13; todas eram movidas a águas. No rio Guarumbi há 2. Do Porto de Cima até as Campinas há 18. Das Campinas até Curitiba, 6. No circuito de Curitiba há 8 , e só uma é movida por animais. De Curitiba à freguesia de Campo Largo e Lapa há mais 8. A expansão ervateira faz surgir a localidade de Porto de Cima com 86 prédios urbanos, arruamentos regulares, 8 lojas de negócios, 10 armazéns de molhados e tavernas e 20 fábricas de soque de erva." (VIEIRA DOS SANTOS apud OLIVEIRA, 2001)

9 "Também o interior transformou-se com a crescente importância da indústria do mate, pois a intensificação do extrativismo favoreceu a ocupação de áreas basicamente inexploradas. Neste caso situa-se o deslocamento de antigos habitantes de Campo Largo no sentido dos atuais municípios de São João do Triunfo, São Mateus, Rio Claro, Mallet, Rebouças, Irati." (MACEDO apud TRINDADE, ANDREAZZA, p.39, 2001). 286
}

Revista da Universidade Vale do Rio Verde, Três Corações, v. 15, n. 2, p.278-295, ago./dez. 2017 
jornaleiros de engenho, desestruturando a agricultura de subsistência.

O quadro seguinte mostra os proprietários de engenhos do mate na terceira década do século XIX:

QUADRO 1 - SENHORES DE ENGENHO DE ERVA MATE NA DÉCADA DE 1830

\begin{tabular}{|c|c|}
\hline $\begin{array}{l}\text { ENGENHOS NO } \\
\text { LITORAL } \\
\end{array}$ & $\begin{array}{c}\text { ENGENHOS SERRA } \\
\text { ACIMA }\end{array}$ \\
\hline $\begin{array}{l}\text { Antonio Vieira dos } \\
\text { Santos }\end{array}$ & Antonio Falcão Bastos \\
\hline Fidélis José Carrão & Baltazar Fernandes \\
\hline Hipólito José Alves & Duarte Vaz Torres \\
\hline Ignacio Loyola e Silva & Evaristo Alves de Araújo \\
\hline Ignacio José da Costa & Fidélis José Carrão \\
\hline Joaquim Americo & Gonçalo Francisco \\
\hline Guimarães & Guimarães \\
\hline José Ignacio de Loyola & João Batista de Andrade \\
\hline Manuel Antonio Figueira & João Antonio Ferreira \\
\hline $\begin{array}{l}\text { Manuel Antonio } \\
\text { Guimarães }\end{array}$ & João Antonio Franco \\
\hline Manuel Lourenço Fontes & $\begin{array}{l}\text { João Teixeira de Oliveira } \\
\text { Franco }\end{array}$ \\
\hline $\begin{array}{l}\text { Manuel Gonçalves } \\
\text { Marques }\end{array}$ & Joaquim Elísio Ferreira \\
\hline $\begin{array}{l}\text { Manuel Ribeiro de } \\
\text { Macedo }\end{array}$ & $\begin{array}{l}\text { João de Souza Dias } \\
\text { Negrão }\end{array}$ \\
\hline $\begin{array}{l}\text { Modesto Gonçalves } \\
\text { Cordeiro }\end{array}$ & Manuel Antonio Figueira \\
\hline $\begin{array}{l}\text { Vicente Antonio } \\
\text { Rodrigues Borba }\end{array}$ & Manuel AntonioRatier \\
\hline & $\begin{array}{l}\text { Manuel de Bastos } \\
\text { Coimbra }\end{array}$ \\
\hline & $\begin{array}{l}\text { Manuel Joaquim de } \\
\text { Souza }\end{array}$ \\
\hline & $\begin{array}{l}\text { Manuel José da Cunha } \\
\text { Bittencourt }\end{array}$ \\
\hline & $\begin{array}{l}\text { Manuel Gonçalves de } \\
\text { Moraes }\end{array}$ \\
\hline & Miguel de Oliveira \\
\hline
\end{tabular}

FONTE: OLIVEIRA, 2001.

2 O MATE E AS TRANSFORMAÇÕES SOCIOECONÔMICAS E POLÍTICAS A PARTIR DO FINAL DO SÉCULO XIX

Com a legalização do comércio do mate entre o Paraná e a região platina, em 1722, um pequeno grupo de comerciantes esteve no controle desse mercado, enquanto a produção da erva estava a cargo de um grande número de produtores artesanais autônomos. A universalidade dos conhecimentos técnicos da produção da erva possibilitava o preparo à população, não exigindo, contudo, grande dispêndio de capital.

Estando o comércio nas mãos de poucos e a produção dispersa entre a população, a concentração dos lucros ficava com os primeiros, que no decorrer do tempo, verificando a necessidade do aprimoramento de novas técnicas e do controle das fraudes nesta etapa, foram expandindo sua atuação no processo produtivo com a inserção de casa de soque para a conclusão do beneficiamento do mate, bem como dos aparatos necessários à exportação.

Ao término do século XVIII, segundo PEREIRA (1996), com a inserção de casas de soque, observou-se a passagem de um sistema de putting-out para um sistema fabril, e, entre as décadas de 1820 ou 1830, tal "transformação" pode ser evidenciada com a introdução da tração hidráulica nestas casas. Houve uma organização hierárquica de trabalho de caráter fabril, propiciando um aumento no ritmo de acumulação.

Segundo IANNI (1988), a socioeconomia do mate "teve a possibilidade de desenvolver-se internamente", por não ser dominada por capitais do exterior. No entanto, foi construída no árduo processo da formação das novas personalidades da história 287

Revista da Universidade Vale do Rio Verde, Três Corações, v. 15, n. 2, p.278-295, ago./dez. 2017 
paranaense do século XIX. A "burguesia industrial do mate", segundo PEREIRA (1996), tal como veio a se constituir, não préexistia à sua indústria. Ela formou-se no mesmo processo em que se formaram os produtores rurais de mate e os jornaleiros fabris dessa indústria. Já MAGALHÃES (1972, p.49) menciona que:

É óbvio que essa burguesia industrial não era uma reprodução idêntica das burguesias industriais européia ou norte-americana, nem era idêntica à burguesia industrial que se desenvolvia no Brasil em função do processo de industrialização por substituição de importações. Mas, nem por isso, era menos burguesia industrial. Seu poder decorria da propriedade de bens de capital, as relações de trabalho eram já predominantemente assalariadas desde a época em que o Brasil ainda dominava o escravagismo.

Os elementos que descrevem a construção de uma burguesia são fundamentalmente elementos distintivos que se criam na relação de uma certa classe com as outras e que se apresentam, na maioria das vezes, de maneira cultural, na forma de relações e trocas simbólicas, e no surgimento de um sistema de disposições de julgamento e consagração próprio (BOURDIEU, 2001).

Porém, LINHARES (1969), que não utiliza a denominação de burguesia para esta atividade econômica, ressalta a formação de uma elite ervateira até 1876 , a primeira que o Paraná teve com base em sua riqueza econômica mais importante, a qual fez viscondes e barões, criando a pequena aristocracia titulada de sociedade paranaense.

Coube à burguesia do mate o reordenamento econômico da sociedade paranaense em torno do trabalho livre e do livre mercado. Esta burguesia, de caráter eminentemente livre-cambista, sustentava mesmo em períodos de crise em que o estado, dominado pelos fazendeiros procurava intervir, a liberdade do comércio. (PEREIRA, 1996)

Dentre as personalidades de grande destaque no Estado nas décadas que antecedem o século XX, está Ildefonso Pereira Correia, Barão do Serro Azul, ativista das iniciativas de progresso local e importante empresário no cenário industrial paranaense, auxiliando no processo de industrialização da erva-mate, bem como do pinho (COSTA apud HOLLEBEN, 2004, p.49).

Sobre à ação empresarial e seus desfechos na estrutura social, SCHUMPETER apud COSTA (1981) pressupõe que:

\begin{abstract}
Decerto, a função empreendedora leva a certas categorias sociais o empreendedor bemsucedido e sua família. Também pode deixar a sua marca numa época da História Social, pode criar um estilo de vida, ou sistemas de moral e de valores estéticos em si mesma, contudo, não indica mais uma situação de classe do que pressupões outra. E as categorias sociais que possam ser atingidas não são, como tal, uma posição de empreendedor, mas se caracterizam como de latifundiário ou de capitalista, de acordo com o modo de utilizar os lucros da empresa. (idem, p.108)
\end{abstract}

Barão do Serro Azul, genuinamente empresário capitalista, merece uma abordagem mais pormenor, pela sua atuação de maior destaque no cenário paranaense 
neste período. Inicialmente, Ildefonso acumulou certa quantidade de capitais com a comercialização da erva-mate. Em 1872, com a colaboração de David Antônio da Silva Carneiro, entra para o ramo industrial do mate através de seu engenho, em Antonina, produzindo um produto para exportação com o seu próprio nome. (COSTA, 1981)

Alguns anos mais tarde, com a lucratividade deste empreendimento e as melhores condições viárias, Barão transfere sua indústria para Curitiba, na região do Batel, e nomeando-a Tibagi. Esta indústria dispunha de maquinaria moderna, além de utilizar o vapor como força motriz, porém, agora, não apenas para moer a erva, mas em outras funções do aparelhamento mecânico especializado (COSTA, 1981).

Segundo Costa (1981), Ildefonso expandiu seu negócios à outras atividades:

...destacando-se a fundação e organização de uma litografia a vapor, a Impressora Paranaense constituindo, ainda hoje, uma das mais importantes empresas no seu setor, no Paraná. Colaborou ainda com Boaventura Clapp e Francisco Fasce Fontana na Companhia de Ferro Carril de Curitiba, também conhecida por Empresa Curitibana, inaugurada a 8 de novembro de 1887. Os bondes desta empresa fariam o trajeto das suas linhas principiando as 5:30 da manhã e terminando às 22 horas, com pontos terminais no Batel e Fontana (idem, p.55).

Barão do Serro Azul ${ }^{10}$ estendeu sua empresas a atividade madeireira, como

\footnotetext{
${ }^{10}$ No setor cultural, dentre outras manifestações, como "contribui, como tesoureiro da comissão encarregada de angariar donativos e livros, para o aumento do acervo da Biblioteca Pública. Em 1886, fez parte da
}

também fez-se proprietário de outras na atividade ervateira, por exemplo o engenho Iguaçu. Além disso, atuou de forma concreta na política do Estado, sendo deputado provincial em diversas legislaturas, Presidente da Câmara Municipal. (COSTA, 1981, p.54), Presidente e Vice da Província do Paraná e alguns outros cargos de extrema importância para o Estado.

No começo do século XX, em 1906, "o censo registra em Curitiba a existência de importantes engenhos dirigidos pelas famílias Miro, Carneiro, Serro Azul, Fontana, Veiga, Xavier de Miranda, Azevedo, França e Almeida, Guimarães e Leão". (CAROLLO apud PASTRE, 2000).

A indústria ervateira propiciou $\mathrm{o}$ aparecimento de um relevante incremento e também crescimento das atividades que lhe serviam de acessórias e davam-lhe o suporte operacional necessário. Serviços para manutenção dos engenhos, embalagem e transporte do mate, exigiam as atividades diversificadas das empresas. Como exemplo tem-se o desenvolvimento da metalurgia, marcenaria, serrarias, gráfica, e outras. (OLIVEIRA, 2001)

Dentre as indústrias complementares destacam-se aquelas fundadas pelos imigrantes europeus, que trouxeram técnicas mais apuradas. Essas empresas estavam ligadas diretamente à indústria do mate, maior

Comissão Central da organização da Pinacoteca Paranaense, da mesma entidade." (COSTA, 1981, p.54) 289 
demandante de serviços, diretamente e indiretamente. $\mathrm{O}$ quadro abaixo demonstra a quantidade e a variedade de fábricas existentes na capital na virada do século XIX:

TABELA 1 - PRINCIPAIS FÁBRICAS E OFICINAS EXISTENTES EM CURITIBA, 1900

\begin{tabular}{|c|c|c|}
\hline FÁBRICAS E OFICINAS & Abs. & $\%$ \\
\hline Fábricas de barricas para erva-mate & 100 & 22,83 \\
\hline Oficina de seleiros & 81 & 18,49 \\
\hline Olarias & 41 & 9,36 \\
\hline Marcenarias & 39 & 8,9 \\
\hline Fábricas para beneficiar erva-mate & 25 & 5,7 \\
\hline Oficinas de alfaiataria & 21 & 4,79 \\
\hline Serralherias & 21 & 4,79 \\
\hline Carpintarias & 19 & 4,33 \\
\hline Oficinas de funileiros & 12 & 2,73 \\
\hline Moinhos de farinha & 10 & 2,28 \\
\hline Serrarias & 10 & 2,28 \\
\hline Curtumes & 10 & 2,28 \\
\hline Fábrica de café moído & 10 & 2,28 \\
\hline Oficina de carros & 7 & 1,59 \\
\hline Fábrica de licores e xaropes & 6 & 1,36 \\
\hline $\begin{array}{l}\text { Oficinas de consertos de } \\
\text { instrumentos }\end{array}$ & 5 & 1,14 \\
\hline Fábricas de águas gasosas & 5 & 1,14 \\
\hline Outros & 16 & 3,6 \\
\hline
\end{tabular}

FONTE: RIBEIRO APUD MAGALHÃES (2001, P. 130)

A intensificação da atividade ervateira, sobretudo no século XIX, proporcionou ao estado profundas transformações: "assistiu-se à emergência e consolidação de processos de industrialização e urbanização" (PEREIRA, 1996). Este novo ambiente propiciou consideráveis transformações na sociedade, como a modificação dos padrões sociais inexoravelmente ainda mais "europeus", bem como novas instituições viabilizadoras desse processo, e ainda modificações arquitetônicas na capital. Sobre o aspecto urbanizante desse período PEREIRA (apud SANTOS, 2001) afirma que na "economia ervateira, as

unidades produtivas encontram-se preferencialmente nas cidades ou em seus arredores. Quando os engenhos, por algum motivo, instalavam-se fora das cidades, provocavam a imediata urbanização em seu entorno" (p. 33).

Em Curitiba, as grandes modificações datam-se do último quartil do século XIX, período no qual o enriquecimento e a ascensão social de várias famílias já havia se consolidado e a cidade já havia incorporado várias modificações por esse enriquecimento. Cabe salientar ainda que "os estrangeiros foram agentes de transformações. Nas cidades, porém, contribuíram de forma peculiar para a construção de uma nova forma de viver urbano que iria caracterizar o cotidiano dos paranaenses na virada do século" (TRINDADE; ANDREAZZA, p.60, 2001).

Em oposição aos numerosos clubes recreativos criados pelos imigrantes estrangeiros em Curitiba, a elite local, principalmente ligado ao mate, funda o Clube Curitibano, em 1882. O objetivo era fundar um clube que agregasse pessoas de origem nacional para fins recreativo e também cultural. Ildefonso Pereira esteve à frente deste empreendimento recreativo e social como um dos fundadores, e sendo seu primeiro presidente.

Em 1889, tendo em vista a imigração, o desenvolvimento da indústria, principalmente a ervateira e a madeireira, e a 
via férrea que ligava o planalto ao litoral, a discussão sobre a implantação de uma estrutura econômico-financeira bancária ganha corpo, e o Banco Mercantil e Industrial do Paraná é fundado, com sede em Curitiba, com objetivo de "proteger e desenvolver o crédito individual e geral da província." (COSTA, 1981, p.66-67). O Barão do Serro Azul esteve, novamente, entre seus fundadores.

$$
\text { Conforme apresentação de }
$$
WACHOWICZ (1983), “a mecanização da produção levou a uma transformação referente ao aspecto de trabalho. A escravidão foi substituída pelo trabalho assalariado. A complexidade decorrente da contínua industrialização passou a exigir gradativamente mais um trabalhador alfabetizado". Assim deu-se o interesse na educação no Paraná, para satisfazer a necessidade das indústrias, em especial a ervateira. Já para MAGALHÃES (1972), o ensino primário vinha atender a necessidade, denominada pelos agentes do Governo, de "abrasileira" os imigrantes estrangeiros.

Em 1870, é instituída na capital a Escola Normal para que os indivíduos interessados no ofício da instrução elementar pudessem lecionar. Dentre os fatores que possibilitaram o início da Escola Nova ${ }^{11}$, no

11 Medidas de organização e sistematização da educação paranaense, as quais, inspiradas pelo ideário modernizante do ensino paulista, dentre outras "medidas destacam-se a reforma do programa do ensino primário, a separação da Escola Normal do Ginásio, a reorganização das escolas primárias em
Paraná, em meados da década de 1930, estão a modernização da indústria ervateira e a intensificação do comércio, a pressão dos imigrantes europeus entre outros por escolas e professores, como pré-requisito para melhores posições na organização do trabalho bem como na sociedade, e o entendimento por parte do governo local de que, com a crescente industrialização era preciso uma mudança na estrutura educacional (MIGUEL, VIEIRA, 2005, p. 4). A indústria ervateira proporcionou também a criação da Universidade Federal do Paraná, para suprir a demanda das elites pelos "moldes" educacionais europeus.

A economia ervateira contribuiu ainda para o "surgimento de entidades de classe. A organização operária em Curitiba começa no século XIX com a fundação da Sociedade Beneficente dos Trabalhadores da Erva-Mate (1896). Os ervateiros fundam em 1887 a Associação Paranaense Propagadora da ErvaMate que em 1938 passou a Instituto do Mate do Paraná. ${ }^{12}$ " (HOLLEBEN, 2004)

Em 1938, em um ambiente caótico como o da superprodução, e diante de um estado de coisas tão aflitivo - a indústria estava às portas da falência, a erva-mate sem preço certo ao produtor - este instituto passa a ser denominado Instituto Nacional do Mate.

núcleos com maior índice de população, adoção de uniformes pelos alunos, bem como, de livros didáticos pelas escolas" (MIGUEL, VIEIRA, 2005, p. 4)

${ }^{12}$ Instituído com a finalidade de salvar a erva- mate da crise, ou até mesmo de sua extinção. Este colapso foi impulsionado, entre outros fatores, pela grande depressão de 29. 
Dentre as medidas tomadas por esta instituição estavam à regulamentação da exportação via cotas aos exportadores, regulando os sistemas de vendas no mercado externo. Depois desta medida estrutural, bastava olhar para o produtor, que entre cerca de 20 mil produtores espalhados nos três estados do sul do Brasil, 15 mil se localizam no Paraná. (LINHARES, 2000)

É também nesse contexto de urbanização que os primeiros problemas sociais tornam-se questão de estado, a população é disciplinada, o que antes era resolvido pelas elites locais é gradativamente transferido ao estado, são criadas os corpos policiais, hospitais psiquiátricos, orfanatos e prisões. O movimento operário também se fez presente no Paraná, segundo MAGALHÃES (2001, p. 39) "a primeira greve que adquire relevância na impressa é a greve dos sapateiros, em 1906." Essa greve é relatada como a primeira em Curitiba e atraiu trabalhadores de outros ramos, influenciados pelos imigrantes que trouxeram idéias socialistas e anarquistas, o estado reprimiu fortemente as greves e na greve geral de 1917, que não teve o mesmo impacto de São Paulo, a repressão foi com mais força ainda, nesse mesmo ano foi criado Paraná a Delegacia de Ordem Política e Social (DOPS), visando combater os anarquistas e as idéias nazistas, cujo alvo eram os imigrantes alemães.

\section{CONSIDERAÇÕES FINAIS}

A atividade ervateira no Paraná tornou-se importante instrumento de renda e receita a partir de meados do século XIX, já que anteriormente, esta atividade extrativa era de pouca rentabilidade e não despertou maiores interesses por parte da sociedade.

O período histórico paranaense conhecido entre os economistas por "ciclo do mate" marcou grandes mudanças na estrutura social e econômica do Paraná, num contexto em que a intensificação da atividade econômica e a das trocas comerciais vinham favorecendo o enriquecimento e a ascensão social de novos segmentos da população. Isto trouxe a tona várias questões, como as que se referem à estrutura de poder e classes, enfatizando as mudanças no ordenamento jurídico e as novas "visões de mundo" introduzidas pela passagem de uma economia predominantemente voltada para a autosubsistência e escambo, durante o século XVIII e parte do século XIX, para uma economia comercial exportadora, no final do século XIX e início do século XX, que mobilizou considerável quantidade de recursos propiciando o aparecimento de uma estrutura industrial mais moderna acompanhada de mudanças culturais e ideológicas, sobretudo na região urbana.

Com o início do processo de beneficiamento da erva-mate deu-se o melhoramento na qualidade do produto tão precária antes dos engenhos. As 
regulamentações acerca da produção e comercialização da erva participaram ativamente nos altos e baixos vivenciados no mercado, bem como os eventos históricos tanto nacionais como internacionais. Porém, as estradas rudimentares inviabilizaram este comércio por longos anos, mas, nas últimas décadas do século XIX, com a construção da Estrada da Graciosa e da ferrovia, esta atividade tornou-se viável.

As relações de trabalho na economia ervateira do Paraná foram de certa forma diversificada, já que trabalhadores livres e escravos - concentrados principalmente nos engenhos - dividiram as tarefas de produção do mate. No primeiro planalto não houve uma relação entre a expansão da atividade ervateira e o crescimento da população escrava, pois homens e mulheres livres constituíram-se a principal fonte de trabalho dessa atividade. Porém, nos Campos Gerais, Castro, Lapa, Ponta Grossa, Jaguariaíva, Tibagi, houve relação direta entre $o$ crescimento das atividades pastoris e o crescimento do número de escravos (OLIVEIRA, 2001).

A lucratividade deste negócio, com a introdução de novas técnicas, e racionalização da produção em geral com o aparecimento de indústrias e trabalhadores especializados, e, por vezes, o cenário propício à exportação da erva, proporcionou um interesse ainda maior por parte dos empresários em investir nesta atividade. O aparecimento de uma burguesia industrial ervateira, embora por muitos questionada, deu-se através da expansão das indústrias da erva-mate na região do planalto e litoral do Paraná, que, ainda, propiciaram não somente a ampliação destas empresas como também o surgimento de indústrias complementares ao mate, impulsionada, doravante, pela imigração européia.

$\mathrm{O}$ destaque do empresariado ervateiro como impulsionador de um estilo de vida e novos padrões de comportamento moral e estético, forneceram os elementos primordiais para a configuração de uma nova ordem social em Curitiba, ou seja, novas relações de produção da vida matéria e social, e inscreveram seus nomes na história paranaense e fato facilmente observável pela nomeação dos principais logradouros da cidade. Como exemplo desse "processo civilizatório" da economia ervateira, várias instituições foram criadas, caso da Universidade Federal do Paraná, da Associação Comercial do Paraná, denominada instituição burguesa por excelência, e de tantas outras, bem como vários centros de lazer, por exemplo o Clube Curitibano e o Passeio Público.

\section{REFERÊNCIAS BIBLIOGRÁFICAS}

BALHANA, A.; PINHEIRO MACHADO, B.; WESTPHALEN, C.M. História do Paraná. Curitiba: Grafipar, 1969.

BONDARIK, R. ; KOVALESKI, J. L. ; PILATTI, L. A. A produção de erva-mate e a iniciação industrial do Paraná. In: ADM 2006 
- 19. Congresso Internacional de

Administração, 2006, Ponta Grossa. Anais do ADM 2006, 2006. p. 1-8.

BOURDIEU, Pierre. A Economia das Trocas Simbólicas. Ed. Perspectiva, São Paulo, 2001.

CARNEIRO, D. Fasmas estruturais da Economia do Paraná. Curitiba: Imprensa da Universidade do Paraná, 1963.

CARNEIRO, N. Um Precursor da Justiça Social: David Carneiro e a Economia Paranaense. Sem edição, 1965.

COSTA, O. R. G., Ação Empresarial do Barão do Serro Azul; subsídios para o estudo da da industrialização do Paraná. Curitiba: SCE-PR, 1981.

COSTA, S.G., da, A erva-mate. Curitiba: Prefeitura Municipal de Curitiba, 1995.

DEAN, W., A Industrialização de São

Paulo. São Paulo: Difel, 1976.

ELIAS, N., 1994. A sociedade dos indivíduos. Rio de Janeiro: Jorge Zahar Editor.

FURTADO, C. Formação Econômica do Brasil. São Paulo: Cia. Editora Nacional, 1959.

GIDDENS, A., TURNER, J. Teoria social hoje. São Paulo: Editora UNESP, 1999.

HOLLEBEN, C. M, Manifestações autoritárias: o integralismo nos campos gerais (1932-1955). Florianópolis, 2004. 220 $\mathrm{f}$. Tese (Doutorado) Universidade Federal de Santa Catarina.

IANNI, O. As Metamorfoses do Escravo. Curitiba: Hucitec, 1988.

KRETZEN, J. As Grandes Potências Econômicas no Estado do Paraná. Curitiba: Escritório Sul-Brasil Econômico Ltda., 1951.

LEANDRO, J. A. Devastação e tráfico de madeira no litoral do Paraná Provincial in: Revista de história regional, n. 2, v. 4, inv., 1999 - Ponta Grossa.

LEVI-STRAUSS, C. Tristes Trópicos. São Paulo: Companhia das Letras, 1998.
LINHARES, T. História Econômica do

Mate. Rio de Janeiro: José Olimpyo, 1969.

LINHARES, T. Paraná Vivo: um retrato sem retoques. Curitiba: Imprensa Oficial, 2000.

MAGALHÃES FILHO, F. B. de, Evolução Histórica da Economia Paranaense In:

Revista Paranaense de Desenvolvimento, n.28, jan/fev., 1972 - Curitiba.

MIGUEL, M. E. B., VIEIRA, A. M. D. P. A Escola Nova no Parana: avanços e contradições in: Revista Diálogo

Educacional, p. 93-100, n. 14, v.5, jan/abr., 2005 - Curitiba.

PADIS, P. C., Formação de Uma Economia Periférica: O caso do Paraná. Curitiba:SCEPR/Hucitec, 1981.

PASINATO, R. Aspectos etnoentomológicos, socioeconômicos e ecológicos relacionados a cultura da erva mate (ilex paraguariensis) no município de Salto do Lontra. Piracicaba, 2003. 112 f. Dissertação (Mestrado) Escola Superior de Agricultura Luiz de Queiroz.

PASTRE, M. O Lazer na Formação da Sociedade Curitibana e o Clube Curitibano In: Revista de história regional, n. 4, v. 2, inv., 2000 - Ponta Grossa.

PEREIRA, M.R. de M., Semeando Iras Rumo ao Proguesso: Ordenamento Jurídico e econômico da Sociedade Paranaense, 1829. 1889. Curitiba: Editora UFPR, 1996.

OLIVEIRA, D. Urbanização e Industrialização no Paraná. Curitiba: SEED, 2001a. (Coleção história do Paraná; textos introdutórios)

OLIVEIRA, R. C. de, O Silêncio dos Vencedores: genealogia, classe dominante e estado no Paraná. Curitiba: Moinho do Verbo, $2001 b$.

SAINT-HILAIRE, A. de, Viagem a Curitiba e Santa Catarina. Belo Horizonte: Itatiaia; São Paulo: EDUSP, 1978.

SANTOS, C. R. A. dos, Vida Material e Ecônomica. Curitiba: SEED, 2001. (Coleção história do Paraná; textos introdutórios) 
TRINDADE, E. M. C. de, ANDREAZZA, M.

L. Cultura e Educação no Paraná. Curitiba:

SEED, 2001. (Coleção história do Paraná;

textos introdutórios)

WACHOWICZ, R. C. Universidade do

Mate: história da UFPR. Curitiba: Edição da APUFPR, 1983.

WESTPHALEN, C. M. Porto de Paranaguá, um Sedutor. Curitiba, SEC-PR, 1998 